\title{
FAKTOR-FAKTOR YANG BERPENGARUH TERHADAP PROFITABILITAS AGROINDUSTRI GULA KELAPA DI KABUPATEN PANGANDARAN
}

\section{FACTORS AFFECTING THE PROFITABILITY OF COCONUT SUGAR AGROINSUSTRY IN PANGANDARAN DISTRICT}

\author{
Ane Novianty, Benidzar M. Andrie \\ Fakultas Pertanian Universitas Galuh \\ J1. RE Martadinata No. 150 Ciamis 46274 \\ *E-mail: ane_165@yahoo.com \\ (Diterima 29-12-2019; Disetujui 20-01-2020)
}

\begin{abstract}
ABSTRAK
Penelitian dilaksanakan dengan tujuan untuk mengetahui factor-faktor yang berpengaruh terhadap profitabilitas pada agroindustry gula kelapa di Kabupaten Pangandaran. Penelitian mengguanakn survai pada 100 perajin gula kelapa yang diambil dari 10 kecamatan di Kabupaten Pangandaran. Faktor-faktor yang berpengaruh terhadap profitabiltas dianalisis dengan menggunakan regresi linier berganda. Hasil penelitian menunjukkan bahwa profitabilitas yang dicapai oleh agroindustri gula kelapa di Kabupaten Pangandaran sebesar 12,93 yang menunjukkan bahwa agroindustri gula kelapa tersebut menguntungkan. Modal dan produksi secara parsial berpengaruh signifikan terhadap profitabilitas agroindustri gula kelapa, sedangkan tenaga kerja dan bahan baku tidak berpengaruh signifikan.
\end{abstract}

Kata kunci: agroindustri, gula kelapa, profitabilitas

\section{ABSTRACT}

The study was conducted with the aim to find out the factors that influence the profitability of coconut sugar agroindustry in Pangandaran District. The study used a survey of 100 coconut sugar crafters taken from 10 districts in Pangandaran District. Factors that affect profitability are analyzed using multiple linear regression. The results showed that the profitability achieved by coconut sugar agro-industry in Pangandaran Regency was 12.93, which showed that the coconut sugar agro-industry was profitable. Capital and production partially have a significant effect on the profitability of coconut sugar agro-industry, while labor and raw materials have no significant effect.

Keywords: agroindustry, coconut sugar, profitability

\section{PENDAHULUAN}

Agroindustri merupakan suatu kegiatan industri yang memberikan nilai tambah serta dapat menciptakan lapangan kerja dalam masyarakat (Timisela dkk, 2012). Manfaat adanya agroindustri antara lain meningkatkan kualitas produk itu sendiri sehingga dapat meningkatkan harga dan nilai tambah (Sukmawati dan Syafrial, 2018). Pengolahan produk pertanian berbasis agroindustri sangat diperlukan untuk meningkatkan nilai ekonomis suatu produk pertanian (Santosa dan Kusumawati, 2014). Kompetensi pelaku agroindustri berkaitan dengan keterampilan, 
pengetahuan, perilaku, karakteristik personal dan motivasi yang berkorelasi dengan keberhasilan dalam melaksanakan usaha (Fadhil dkk, 2017). Potensi pengusaha ini juga sangat ditentukan oleh sikap kewirausahaan yang dapat mendukung pengembangan usahanya, dimana sikap ini dipengaruhi oleh berbagai hal seperti pendidikan dan latihan yang pernah dilakukan (Gunanda dan Elida, 2016).

Pengusaha gula kelapa umumnya dilakukan oleh rakyat pedesaan dan merupakan industri rumah tangga dengan skala usaha yang relatif kecil (Indarwati, 2009). Pendidikan perajin agroindustri umumnya tergolong rendah (Maharani, dkk 2017). Rendahnya pendidikan ini berpengaruh terhadap kompetensi perajin dalam melaksanakan usahanya.

Bagi perusahaan pada umumnya masalah profitabilitas lebih penting daripada masalah laba, karena masalah laba yang besar saja belumlah merupakan ukuran bahwa prusahaan itu telah dapat bekerja dengan efisien. Dengan demikian yang harus diperhatikan oleh perusahaan tidak hanya bagaimana memperbesar laba tetapi yang lebih penting adalah usaha untuk mempertinggi profitabilitasnya. Besar kecilnya profitabilitas ditentukan oleh dua faktor, yaitu hasil penjualan dan keuntungan usaha. Besar kecilnya keuntungan tergantung pada pendapatan yang merupakan selisih dari penjualan dikurangi dengan biaya usaha (Putra dkk, 2016).

Kelangsungan hidup perusahaan dipengaruhi oleh banyak hal antara lain profitabilitas perusahaan itu sendiri. Selain itu, tingkat pertumbuhan penjualan dapat juga mempengaruhi profitabilitas perusahaan. Semakin tingginya penjualan bersih yang dilakukan oleh perusahaan dapat mendorong semakin tingginya laba kotor yang mampu diperoleh, sehingga dapat mendorong semakin tingginya profitabilitas perusahaan. (Barus dan Leliani, 2013). Pengukuran profitabilitas dapat digunakan untuk mengukur kinerja suatu perusahaan (Deoranto dkk, 2016).

Beberapa penelitian terkait profitabilitas menunjukkan bahwa profitabilitas maupun pendapatan dipenagaruhi oleh modal dan tenaga kerja (Usman dan Fifiliani, 2018); produksi, harga jual produk, biaya tenaga kerja, biaya bahan baku, biaya bahan tambahan dan biaya bahan bakar (Rizal dkk, 2017); bahan baku dan tenaga kerja (Nursamsi dkk, 2017); harga bahan baku, jumlah bahan baku, biaya produksi (Malik dkk, 2017); jumlah produksi, modal, pendidikan, kredit, dan penyuluhan 
berpengaruh signifikan terhadap pendapatan agroindustri gula kelapa (Yuroh dan Maesaroh, 2018).

Berdasarkan uraian di atas, maka penelitian ini dilaksanakan dengan tujuan untuk mengetahui faktor-faktor yang berpengaruh terhadap profitabilitas agroindustri gula kelapa di Kabupaten Pangandaran.

\section{METODE PENELITIAN}

Penelitian dilaksanakan dengan menggunakan metode survai pada agroindustri gula kelapa di Kabupaten Pangandaran. Data yang digunakan dalam penelitian ini terdiri atas data primer dan sekunder. 10 kecamatan diambil sebagai sampel wilayah, dan dari masing-masing kecamatan tersebut diambil 10 perajin sehingga ukuran sampel 100 perajin.

Profitabilitas merupakan hasil bagi antara pendapatan usaha dengan biaya total yang dinyatakan dalam persen (Putra dkk, 2016). Analisis profitabilitas dilaksanakan dengan menggunakan persamaan sebagai berikut (Budiningsih dan Watemin, 2015):

$$
\text { Profitabilitas }=\frac{\pi}{T C} \times 100 \%
$$

Keterangan:

$\pi=$ Keuntungan (Rp/bulan)

$\mathrm{TC}=$ Total cost (biaya total) biaya (Rp/bulan)
Kriteria yang digunakan dalam penilaian profitabilitas adalah: jika profitabilitas $>0$, berarti agroindustri menguntungkan; jika profitabilitas $=0$, berarti agroindustri mengalami impas; dan jika profitabilitas $<0$, berarti agroindustri tidak menguntungkan.

Faktor-faktor yang berpengaruh terhadap profitabilitas agroindustry gula kelapa dianalisis dengan menggunakan persamaan regresi linier berganda sebagai berikut:

$\mathrm{Y}=\mathrm{b}_{0}+\mathrm{b}_{1} \mathrm{X}_{1}+\mathrm{b}_{2} \mathrm{X}_{2}+\mathrm{b}_{3} \mathrm{X}_{3}+\mathrm{b}_{4} \mathrm{X}_{4}$

Dimana:

$\mathrm{Y}=$ profitabilitas $(\%)$

$\mathrm{X}_{1}=\operatorname{modal}(\mathrm{Rp})$

$\mathrm{X}_{2}=$ Produksi $(\mathrm{kg})$

$\mathrm{X}_{3}=$ Tenaga kerja $(\mathrm{HOK})$

$\mathrm{X}_{4}=$ Bahan baku $(\mathrm{kg})$

\section{HASIL DAN PEMBAHASAN}

\section{Profitabilitas agroindustri gula kelapa}

Dalam setiap bisnisnya perusahaan pasti menginginkan laba. Kemampuan untuk memperoleh laba dalam dunia bisnis disebut dengan profitabilitas. Profitabilitas perusahaan sangat ditentukan oleh faktor internal dan eksternal perusahaan. Faktor internal meliputi kemampuan manajemen, kompetensi karyawan, sistem reward dan punishment, asset yang digunakan, utang, 
penjualan serta kompetensi perusahaan menurut pendekatan resources based views (Winarno dkk, 2015).

Profitabilitas adalah kemampuan perusahaan dalam menghasilkan laba (Minanari, 2018). Profitabilitas adalah kemampuan menghasilkan laba/profit selama periode tertentu dengan menggunakan aktiva atau modal, baik modal secara keseluruhan maupun modal sendiri (Barus dan Leliani, 2013).

Profitabilitas agroindustri gula kelapa di Kabupaten Pangandaran dapat dilihat pada Tabel 1.

Tabel 1. Profitabilitas Agroindustri Gula Kelapa

\begin{tabular}{|c|c|c|}
\hline No & Uraian & Jumlah \\
\hline \multirow[t]{5}{*}{1.} & Biaya Tetap Total (TFC) (Rp) & $31.821,06$ \\
\hline & a. Penyusutan (Rp) & $2.375,56$ \\
\hline & b. Pajak bumi dan bangunan (Rp) & 2,58 \\
\hline & c. Sewa pohon (Rp) & $21.590,40$ \\
\hline & d. Bunga modal tetap (Rp) & $7.852,51$ \\
\hline \multirow[t]{8}{*}{2.} & Biaya Variabel Total (TVC) (Rp) & $68.449,16$ \\
\hline & a. Natrium (Rp) & $1.274,00$ \\
\hline & b. Kayu bakar (Rp) & $12.248,00$ \\
\hline & c. Plastik (Rp) & 500,00 \\
\hline & d. Parutan kelapa (Rp) & 829,50 \\
\hline & e. Kapur sirih (Rp) & 306,40 \\
\hline & f. Tenaga kerja (Rp) & $36.400,00$ \\
\hline & g. Bunga modal 325ariable (Rp) & $16.891,26$ \\
\hline 3. & Biaya Total (TC) (Rp) & $100.270,22$ \\
\hline \multirow[t]{3}{*}{4.} & Penerimaan (Rp) & $113.232,00$ \\
\hline & Jumlah produksi (kg) & 9,44 \\
\hline & Harga jual produk (Rp/kg) & $12.000,00$ \\
\hline 6. & Pendapatan (Rp) & $12.961,78$ \\
\hline 8. & Profitabilitas & 12,93 \\
\hline
\end{tabular}

Sumber: Analisis Data Primer, 2019
Tabel 1 menunjukkan bahwa profitabilitas yang dicapai oleh agroindustri gula kelapa di Kabupaten Pangandaran sebesar 12,93 yang menunjukkan bahwa agroindustri gula kelapa tersebut menguntungkan.

\section{Faktor-faktor yang berpengaruh terhadap profitabilitas}

Faktor-faktor yang berpengaruh terhadap profitabilitas agroindustry gula kelapa di Kabupaten Pangandaran dianalisis dengan menggunakan regresi linier berganda sebagaimana dapat dilihat pada Tabel 2 .

Tabel 2. Faktor-faktor yang Berpengaruh Terhadap Profitabilitas Agroindustri Gula Kelapa

\begin{tabular}{llll}
\hline Variabel & Parameter & Std & t-hit \\
\hline Konstanta & 25,544 & 3,999 & $6,404^{*}$ \\
Modal & $-6,151$ & 0,918 & $-6,704^{*}$ \\
Produksi & 6,031 & 0,555 & $19,871^{*}$ \\
Tenaga kerja & 0,934 & 0,766 & 1,220 \\
Bahan baku & $-0,011$ & 0,105 & $-0,107$ \\
\hline $\mathrm{R}^{2}$ & $=0,567$ & & \\
F-hit & $=31,161^{*}$ & & \\
\hline
\end{tabular}

Tabel 2 menunjukkan bahwa modal, produksi, tenaga kerja dan bahan baku secara simultan berpengaruh signifikan terhadap profitabilitas agroindustri gula kelapa. Nilai koefisien determinasi sebesar 56,7\% menunjukkan 
bahwa profitabilitas tersebut sebesar $56,7 \%$ dipengaruhi oleh variabel yang ada dalam model, sedangkan 43,3\% dipengaruhi oleh variabel lain yang tidak dimasukan dalam model.

Modal dan produksi secara parsial berpengaruh signifikan terhadap profitabilitas agroindustri gula kelapa, sedangkan tenaga kerja dan bahan baku tidak berpengaruh signifikan.

\section{KESIMPULAN DAN SARAN}

\section{Kesimpulan}

Profitabilitas yang dicapai oleh agroindustri gula kelapa di Kabupaten Pangandaran sebesar 12,93 yang menunjukkan bahwa agroindustri gula kelapa tersebut menguntungkan.

Modal, produksi, tenaga kerja dan bahan baku secara simultan berpengaruh signifikan terhadap profitabilitas agroindustri gula kelapa.

Modal dan produksi secara parsial berpengaruh signifikan terhadap profitabilitas agroindustri gula kelapa, sedangkan tenaga kerja dan bahan baku tidak berpengaruh signifikan.

\section{Saran}

Pengusaha gula kelapa disarankan untuk meningkatkan skala produksinya sehingga profitabilitas yang dicapai mengalami peningkatan.

\section{UCAPAN TERIMA KASIH}

Ucapan terima kasih disampaikan kepada Kemenrsitekdikti yang telah membiayai penelitian ini melalui skema Penelitian Dosen Pemula Tahun Anggaran 2019/2020.

\section{DAFTAR PUSTAKA}

Barus, A.C. dan Leliani. (2013). Analisis Faktor-faktor yang Mempengaruhi Profitabilitas pada Perusahaan Manufaktur yang Terdaftar di Bursa Efek Indonesia. Jurnal Wira Ekonomi Mikroskil 3(2): 111-121.

Deoranto, P., Harwitasari, A. dan Ikasari, D.M. (2016). Analisis Produktivitas dan Profitabilitas Produksi Sari Apel dengan Metode American Productivity Center di KSU Brosem. Industria: Jurnal Teknologi dan Manajemen Agroindustri 5(3): 114-124.

Fadhil, R., Maarif, M.S., Bantacut, T. dan Hermawan, A. (2017). Model Strategi Pengembangan Sumber Daya Manusia Agroindustri Kopi Gayo dalam Menghadapi Masyarakat Ekonomi ASEAN. Jurnal Manajemen Teknologi, 16(2): 141-156.

Yuroh, F. dan Maesaroh, I. (2018). Faktor-faktor yang Berpengaruh Terhadap Pendapatan dan Produktivitas Agroindustri Gula Kelapa di Kabupaten Pangandaran. Mimbar Agribisnis 4(2): 254-273. 
Gunanda, R. dan Elida, S. (2016). Analisis Agroindustri Kedelai di Kecamatan Seberida Kabupaten Indragiri Hulu Privinsi Riau. Jurnal Agribisnis, 18(2): 1-18.

Indarwati, I. (2009). Efisiensi Produksi Pada Agroindustri Gula Kelapa di Kecamatan Cilongok Kabupaten Banyumas. Majalah Ilmiah Ekonomika, 12(3): 109-179.

Maharani, E., Edwina, S., Rosnita, dan Muslimah, S. (2017). Keragaan Karakteristik Pengrajin dan Agroindustri Gula Aren di Kecamatan Benai Kabupaten Kuantan Singingi. UNES Journal of Agricultural Scienties, 1(1): 7487.

Malik, S.R., Antara, M. dan Sulaeman. (2017). Faktor-faktor yang Memengaruhi Pendapatan Industri Bawang Goreng di Kota Palu. J. Agroland 24(1): 36-48.

Nursamsi, Siregar, S. dan Iqbal, N. (2017). Analisis Faktor-faktor yang Mempengaruhi Pendapatan Usaha Emping Melinjo Skala Rumah Tangga. Journal of Agribusiness Science 01(01): 66-72.

Putra, D.M., Napitupulu, D. dan Elwamendri. (2016). Dampak Krisis Ekonomi Terhadap Profitabilitas Agroindustri Keripik Tempe di Kabupaten Tebo. Sosio Ekonomika Bisnis 19(1): 1-8.

Rizal, Dewi, E.F.E. dan Muksin. (2017). Pengaruh Faktor Sosial, Strategi Usaha dan Ekonomi Terhadap Peningkatan Pendapatan Agroindustri Kerupuk di Kelurahan Mangli Kecamatan Kaliwates Kabupaten Jember. Prosiding
Industrial Research Workshop and National Seminar, Politeknik Negeri Bandung, pp. 333-341.

Santosa, P.B. dan Kusumawati, A. (2014). Nilai Tambah Usaha Agroindustri Labu Menjadi Kuaci dan Pia (Studi Kasus Industri Rumah Tangga Mugi Rahayu, Desa Getasan, Kecamatan Getasan Kabupaten Semarang). Jurnal Dinamika Ekonomi \& Bisnis, 11(2): 107-119.

Sukmawati, D.A. dan Syafrial. (2018). Analisis Nilai Tambah Gula Kelapa dan Strategi Pengembangan Pada Agroindustri Kecap Cap "SRK" di Kabupaten Pacitan. Jurnal Ekonomi Pertanian dan Agribisnis (JEPA), 2(1): 29-40.

Timisela, N.R., Turukay, M., Parera, W.B. dan Lawalata, M. (2012). Efisiensi Relatif Agroindustri Pala Banda Dengan Pendekatan Data Envelopment Analysis (DEA). SEPA, 9(1): 25-33.

Usman, U. dan Fifiliani. (2018). Faktorfaktor yang Mempengaruhi Pengusaha pada Usaha Tanaman Pala (Studi kasus: Desa Panjupain dan Desa Lhok Rukam Kecamatan Tapaktuan). Jurnal Ekonomi Pertanian Unimal 01(02): 40-46.

Winarno, Hidayati, L.N. dan Darmawati, A. (2015). Faktor-Faktor Yang Memengaruhi Profitabilitas Perusahaan Manufaktur yang Listed di Bursa Efek Indonesia. Jurnal Economia, 11(2): 143-149.

Yurhaya dan Rauf, R.A. (2016). Analisis Profitabilitas Usaha Kopi Bubuk pada Industri Bumi Mutiara di Kota Palu. J. Agroland 23(2): 149-156. 